\title{
REFLEXÕES A RESPEITO DA NECESSIDADE DE PARTICIPAÇÃO DOS MUNICÍPIOS NA FORMULAÇÃO E NA IMPLEMENTAÇÃO DE POLÍTICAS DE SEGURANÇA PÚBLICA
}

\author{
Cláudio Alberto Gabriel Guimarães ${ }^{1}$ \\ Paulo Fernando Soares Pereira ${ }^{2}$
}

\begin{abstract}
"A questão da segurança é, historicamente, inerente à noção de cidade. Em bom rigor, há duas noçôes fundamentais que estão na base do nascimento das cidades. São elas, a noção de (viver em) sociedade e a noção de (viver em segurança). Ora, sem estas duas qualidades, as cidades tornam-se simples aglomerados de coisas e pessoas".

Fernandes (2009, p. 69)
\end{abstract}

\section{Resumo:}

Objetiva-se com o presente artigo refletir a respeito das várias possibilidades, no cenário constitucional atual, de maior participação do Município brasileiro na formulação e na implantação de políticas de segurança pública, principalmente sob o aspecto preventivo, através da organização do espaço urbano, articulação com outros entes, o resgate dos conceitos de civismo, comunidade, espaços e serviços, bem como apresentar alguns avanços legislativos, vigentes e em discussão, em torno da questão.

Palavras-chave: Segurança pública. Prevenção. Participação dos Municípios brasileiros.

\section{INTRODUÇÃO}

A segurança pública e, consequentemente, os assuntos que lhe são correlatos, como a violência urbana, o controle social formal e informal, o papel dos vários atores sociais na temática, dentre tantos outros recortes, são temas cuja discussão e aprofundamento não podem mais ser postos fora das prioridades de todos os entes e entidades - públicas e privadas - que possuem alguma parcela de responsabilidade em tal área de atuação governamental.

\footnotetext{
${ }^{1}$ Promotor de Justiça do Estado do Maranhão. Doutor em Direito Público pela Universidade Federal de Pernambuco, com área de concentração em Direito Penal. Doutor em Direito pela Universidade Federal de Santa Catarina, com área de concentração em Criminologia. Professor Pesquisador do CNPq e UNICEUMA. Professor Adjunto da Universidade Federal do Maranhão.

E-mail: calguimaraes@yahoo.com.br

${ }^{2}$ Mestrando do Programa de Pós-Graduação em Direito e Instituições do Sistema de Justiça, da Universidade Federal do Maranhão - UFMA. Procurador Federal no Estado do Maranhão. Professor Universitário junto ao Departamento de Direito da Faculdade Estácio São Luís. E-mail: pfspereira@bol.com.br
} 
O presente estudo tem como objetivo principal fomentar a discussão a respeito da possibilidade do Município brasileiro agir de forma mais efetiva na formulação e na implementação de políticas preventivas de segurança pública.

Teoricamente, há uma riqueza de estudos sobre a temática da segurança pública e prevenção da violência e da criminalidade, tanto no Brasil quanto no exterior ${ }^{3}$, sendo que o trabalho procurará dialogar, com as devidas ponderações, com os diversos marcos teóricos, aproveitando o que tem sido discutido de forma mais aprofundada, sem preconceitos ${ }^{4}$ ideológicos, a fim de apresentar, ao final, alguma contribuição para o tema.

Sob esse enfoque, a discussão perpassa pela função do Município, no Estado Federal brasileiro, como matéria em evolução, na qual, tem-se a sua intensa participação na formulação e implantação de determinadas políticas públicas, a exemplo da saúde, assistência social, educação, trânsito, política urbana ${ }^{5}$ etc., e, por outro lado, em sua diminuta atuação no que diz respeito à segurança pública, já que a Constituição privilegiou os órgãos da União e dos Estados para o seu bom desempenho, o que não tem sido suficiente, porém, para deixar a violência e a criminalidade em níveis toleráveis.

Por sua vez, a política de camburão, sirene e cassetete se mostra insuficiente e não combate o fenômeno da violência em sua raiz, mas apenas em seu estágio conclusivo. Segurança se faz com prevenção e com inteligência das informações ${ }^{6}$, inclusive na gestão e interação dos diversos órgãos estatais ${ }^{7}$.

Ora, nesse sentido, para que a violência e a criminalidade sejam efetivamente prevenidas, as instituições jurídicas precisam de aperfeiçoamento constante e esse parece ser o caso da participação da municipalidade na formulação e na implementação de políticas preventivas de segurança pública, as quais devem considerar a violência e a criminalidade em seu nascedouro ${ }^{8}$.

\footnotetext{
${ }^{3}$ Indicamos a leitura de Andrade (2003b), Christie (2009, p. 17-18) e Garland (1999).

${ }^{4}$ Sobre preconceitos nas ciências do espírito, cfr. Gadamer (1997, p. 709), para quem "não existe compreensão que seja livre de todo preconceito, por mais que a vontade do nosso conhecimento tenha de estar sempre dirigida, no sentido de escapar ao conjunto de nossos preconceitos. No conjunto da nossa investigação evidencia-se que, para garantir a verdade, não basta o gênero de certeza, que o uso dos métodos científicos proporciona".

${ }^{5}$ Sobre esses temas, respectivamente, saúde (cfr. a Lei no 8.80/90, que trata a respeito da organização do Sistema Único de Saúde SUS, em especial o art. 15, com as atribuições comuns de União, Estados e Municípios, e art. 18, com atribuições de incumbência dos Municípios), assistência social (cfr. a Lei no 8.742/93, que dispõe sobre a organização da Assistência Social, dispondo, inclusive que, no art. 11, "as ações das três esferas de governo na área de assistência social realizam-se de forma articulada, cabendo a coordenação e as normas gerais à esfera federal e a coordenação e execução dos programas, em suas respectivas esferas, aos Estados, ao Distrito Federal e aos Municípios"), educação (cfr. a Lei no 9.394/96, que estabelece as diretrizes e bases da educação nacional, em especial os arts. 11 e 18, que definem as atribuições dos Municípios), trânsito (cfr. a Lei no 9.503/97, que institui o Código de Trânsito Brasileiro, disciplinando, no art. $7^{\circ}$ a 25 as atribuições da União, Estados e Municípios) e urbanismo (cfr. a Lei no 10.257/2001, conhecido como o Estatuto das Cidades).

${ }^{6}$ Sobre o estudo científico da inteligência, principalmente após o 11 de setembro, e sua relação com a segurança, cfr. Graça (2009).

${ }^{7}$ Sobre gestão de informações em segurança pública, cfr. Beato Filho (2012).

${ }^{8}$ Evidentemente, há espécies de violência e criminalidade que ultrapassam os limites dos Municípios, o que, por consequência, foge ao objeto desta discussão, pois o que se pretende abordar, em verdade, é, tão somente, a possibilidade de o Município agir preventivamente nos tipos de violência e criminalidade que são específicos de seus limites territoriais.
} 
Parece, dessa forma, que o ente que tem maiores chances de conhecer tal realidade, por estar mais próximo da realidade criminógena ${ }^{9}$, é o Município, como agente formulador de políticas públicas preventivas, em um número bastante significativo de delitos.

Assim, o trabalho abordará, primeiramente, os limites constitucionais de atuação dos diversos entes federativos na área de segurança pública, seguindo-se com a abordagem em torno do Município na Federação brasileira e concluindo com a temática a respeito das várias formas pelas quais os Municípios brasileiros poderiam coadjuvar nas políticas públicas de segurança pública, apresentando-se um panorama legislativo vigente e o qual se pretende implantar.

\section{OS LIMITES CONSTITUCIONAIS DE ATUAÇÃO DOS DIVERSOS ENTES FEDERATIVOS NA ÁREA DE SEGURANÇA PÚBLICA}

\section{A segurança como bem coletivo e a manutenção da ordem pública}

O urbanismo moderno, desde a Carta de Atenas ${ }^{10}$, sintetiza as quatro funções das cidades: habitar, trabalhar, recrear e circular. A segurança pública objetiva, dentre outras coisas, exatamente, assegurar que as pessoas possam usufruir de tais funções.

Na perspectiva acima, a expressão segurança provém do latim ( securitas), que significa tranquilidade de espírito e desnecessidade de cuidados. No entanto, etimologicamente, o duplo sentido de securitas significa, igualmente, o desleixo, o descuido e a indiferença (GRAÇA, 2009), dando-se a ideia de circulação ou de se estar parado sem preocupações.

Para Silva (2009, p. 778),

"a segurança púbica consiste numa situação de preservação ou restabelecimento da convivência social que permite que todos gozem de seus direitos e exerçam suas atividades sem perturbação de outrem, salvo nos limites de gozo e reivindicação de seus próprios direitos e defesa de seus legítimos interesses"

, sendo uma atividade dinâmica, envolvendo vigilância, prevenção e repressão às condutas delituosas.

Com a definição do conceito de segurança pública ${ }^{11}$, não se pode esquecer que a manutenção da ordem pública é considerada um dos principais bens coletivos da sociedade moderna, sendo que o combate à criminalidade constitui uma atribuição estruturante do Estado nas sociedades contemporâneas, pois, além de prover saúde e educação, bem como outros serviços que garantam o bem-estar social, o Estado deve zelar pela

\footnotetext{
${ }^{9}$ Sobre o tema Agnew (2009, p. 169-173).

${ }^{10}$ Elaborada no IV Congresso Internacional de Arquitetura e Urbanismo - CIAM, de 1933, mas tornada pública, por Le Corbusier, apenas em 1943, em Paris.

${ }^{11}$ Veja-se, também, o conceito de Canotilho e Moreira (1993, p. 184), para quem a segurança é um direito "garantia de exercício seguro e tranquilo dos direitos, liberto de ameaças e agressões".
} 
preservação do patrimônio e integridade física dos cidadãos, por meio do aparato burocrático que passa a assumir a provisão do bem coletivo, particularmente através da instituição do sistema prisional, de organizações policiais profissionalizadas e de um sistema judicial formalizado (SAPORI, 2007), denominado controle social formal ${ }^{12}$.

Nesse sentido, a segurança pública, como bem jurídico fundamental, alçado ao mesmo nível de direitos já consagrados no cenário constitucional, como a vida, a liberdade, a igualdade e à propriedade (art. $5^{\circ}$, caput, da $\mathrm{CF})$, é bem escasso, de valor individual e supra-individual para o qual contribuem vários fatores, sejam eles materiais (mecânicos e eletrônicos, informáticos, digitais etc.) e humanos, cabendo às instituições de pesquisa aprofundar e dirigir com o objetivo de se criar um espaço físico mais livre, justo, solidário e humano, produzindo estudos para um saber prático que melhore a qualidade de vida das pessoas, conjugando, para tanto, a vertente prática e o saber doutrinal e pragmático, a fim de que este evolua cientificamente (VALENTE, 2009) ${ }^{13}$.

Partindo da premissa segundo a qual a segurança pública, propiciando melhores condições de vida para todos, é considerada um direito humano (PIRES, 2004), a qual garante, dentre outras coisas, o direito de ir e vir, parece haver certo consenso de que há necessidade de se aperfeiçoar o sistema de segurança pública, pois de nada adiantaria conferir-se outros direitos (liberdade, igualdade, propriedade, intimidade etc.) sem a garantia de que os mesmos possam ser usufruídos ${ }^{14}$.

E o aperfeiçoamento do sistema de segurança pública passa pela sua efetividade, o que implica em verificar quais os entes estatais que podem contribuir para o seu pleno funcionamento.

\section{A intervenção da União nas questões envolvendo segurança pública}

A violência é fenômeno complexo e multifacetário, assumindo variadas faces e desconhecedora da estrutura burocrática do Estado. Baratta (1993), através da denominada Criminologia Crítica, chama a atenção para uma de suas mais perversas vertentes, advertindo que a violência estrutural é a repressão das necessidades reais e, portanto, dos direitos humanos no seu conteúdo histórico-social ${ }^{15}$.

Ocorre que, no Brasil, a prevenção da violência e da criminalidade parece ter desconhecido, por muito tempo, o fenômeno da violência sob o enfoque dado pela Criminologia Crítica, o que gerou um quadro

\footnotetext{
${ }^{12}$ Para uma leitura atual a respeito de controle social formal, vide, Guimarães (2013).

${ }^{13}$ Sobre a importância das universidades no estudo da segurança pública, cfr. Costa (2010).

${ }^{14}$ Seria inócuo, por exemplo, o direito de propriedade a uma moradia caso não se permitisse que o cidadão tivesse garantido o seu sossego, ou seja, que se sentisse seguro em sua casa, assim como transitar pelas ruas etc.

${ }^{15} \mathrm{~A}$ violência estrutural, ainda para Baratta (1993), como forma de violência, é a forma geral da violência em cujo contexto se origina, direta e indiretamente, todas as outras formas de violência: individual (quando o agente é um indivíduo), violência de grupo (quando o agente é um grupo social, que se serviria de indivíduos particulares, a exemplo de grupos paramilitares), bem como a violência institucional (quando o agente é um órgão do Estado, um governo, exército ou a polícia, sendo que a mesma pode ter várias formas legais, conforme as leis vigentes num Estado).
} 
insustentável, tendo-se em conta que a estrutura administrativa (burocrática, em sua acepção clássica) não se mostrou suficiente para deixá-la em níveis aceitáveis ${ }^{16}$.

Sob essa razão, houve a necessidade de intervenção da União nas questões de segurança pública ${ }^{17}$, a qual teve como grande passo a instituição do Plano Nacional de Segurança Pública, através da Lei no 10.201/2001, que instituiu o Fundo Nacional de Segurança Pública, com o objetivo de apoiar projetos na área de segurança pública e de prevenção à violência ${ }^{18}$.

Discorrendo a respeito da repartição de atribuições constitucionais em torno da segurança pública, Lima (2011) adverte que a distribuição da competência federativa em torno da segurança pública e da justiça, no Brasil, ao mesmo tempo em que distribui atribuições entre os diversos entes (União, Estados e Distrito Federal), também, condiciona estratégias de planejamento e avaliação dos programas e ações propostas, já que estabelece padrões e modelos de atuação ${ }^{19}$.

Nesse enfoque, é preciso avançar nesse campo, pois os avanços na segurança pública foram residuais e se limitaram a dar caráter civil ao policiamento, retirando-o do campo da "defesa nacional", vigente no modelo anterior a 1988, e das forças armadas; o pacto federativo e o modelo de organização policial (civil e militar) não foram alterados, apesar da presença cada vez mais constante dos Municípios, em que pese a omissão constitucional, na formulação e execução de políticas de prevenção e combate à violência (LIMA, 2011).

\footnotetext{
${ }^{16}$ Sobre o tema White, Haines e Asquith (2012).

${ }^{17}$ Sobre a intervenção da União nas políticas públicas de segurança pública, Barbosa (2008) lembra que, é necessário perceber as continuidades e rupturas entre os sucessivos planos de segurança pública propostos na esfera do governo federal. O primeiro Plano Nacional de Segurança Pública, lançado no segundo governo Fernando Henrique Cardoso (FHC), no ano 2000, assinalou um deslocamento significativo no que diz respeito ao tratamento do assunto até então, pois a segurança pública adentrou a agenda de discussões para assumir um lugar central nos compromissos da União, rompendo com uma postura inercial que deixava os problemas da segurança restritos somente aos Estados e suas polícias e que facultava a reprodução, nas sombras, de antigas práticas policiais marcadas pela arbitrariedade, violência e autoritarismo. Lembra, ainda, por outro lado, que não se pode esquecer que os esforços que antecedem o Plano Nacional, como a criação da Secretaria Nacional de Direitos Humanos e a formulação do primeiro Plano Nacional de Direitos Humanos, bem como a criação da Secretaria Nacional de Segurança Pública (SENASP). Igualmente, sobre a participação do Governo Federal (União) nas questões envolvendo segurança pública, cfr. Vendramini (2010).

${ }^{18} \mathrm{O}$ plano se pauta no apoio a projetos que objetivem, preferencialmente: o reequipamento, treinamento e qualificação das polícias civis e militares, corpos de bombeiros militares e guardas municipais; implantação de sistemas de informações, de inteligência e investigação, bem como de estatísticas policiais; a estruturação e modernização da polícia técnica e científica; programas de polícia comunitária; programas de prevenção ao delito e à violência (art. 4º). É importante destacar que, o Conselho Gestor do Fundo Nacional de Segurança Pública, na avaliação dos projetos, priorizará o ente federado que se comprometer com os seguintes resultados: I - realização de diagnóstico dos problemas de segurança pública e apresentação das respectivas soluções; II desenvolvimento de ações integradas dos diversos órgãos de segurança pública; III - qualificação das polícias civis e militares, corpos de bombeiros militares e das guardas municipais; IV - redução da corrupção e violência policiais; V - redução da criminalidade e insegurança pública; e VI - repressão ao crime organizado ( $\left.\operatorname{art} .4^{\circ}, \$ 2^{\circ}\right)$.

${ }^{19}$ Ainda, para Lima (2011), as reformas legislativas propostas ou implementadas são condição institucional para um planejamento público inovador, seja como a promoção de ações governamentais integradas, articulação entre esferas de governo e sociedade civil organizada e o setor privado, seja com a redução de gastos públicos superpostos.
} 
Com o despertar da União para as questões relacionadas à segurança pública, parece que houve uma maior cobrança em relação aos aspectos da prevenção e da articulação da questão, pois esse ente passou a articular a discussão sobre o tema, bem como passou a traçar diretivas gerais para os demais entes.

\section{Segurança pública, prevenção e articulação}

É difícil conceber a prevenção da violência sem a ação articulada dos órgãos de gestão da segurança pública, sem a participação da população e, mais ainda, sem a participação dos Municípios. Nesse enfoque, para se prevenir, efetivamente, a criminalidade, no Brasil, é preciso partir dos seguintes pressupostos, como lembra Barbosa (2008): a integração intergovernamental (entre a União, Estados e Municípios; entre os poderes Legislativo, Executivo e Judiciário); a gestão intersetorial de projetos (com a participação em cada ente federado de diversos ministérios ou secretarias); o recurso às abordagens interdisciplinares (partindo-se do pressuposto segundo o qual a criminalidade e a insegurança são fenômenos complexos e que, portanto, demandam abordagens múltiplas e diversificadas); a participação comunitária (que busca integrar os organismos da sociedade civil nos esforços de planejamento e execução de programas preventivos); a inserção local (considerando que as dinâmicas criminais ou conflitivas só podem ser compreendidas e abordadas a partir do contexto local); a prevenção situacional (que implica no redesenho do espaço urbano e na melhoria dos serviços de infraestrutura); a prevenção social (baseada no entendimento de que as causas e as dinâmicas criminais estão associadas a fenômenos sociais abrangentes: educação, saúde, cultura, economia etc.).

Sob o viés acima, parece ser fato inconteste que não se faz política de segurança pública e prevenção de violência apenas com o uso de força policial. A adequada prevenção da criminalidade se dá em momento anterior ao direito penal, conquanto as políticas preventivas não devam ser excludentes de políticas repressivas ${ }^{20}$, o que constituiria um equívoco ${ }^{21}$.

\footnotetext{
20 "Os desafios para a prevenção do crime têm sido sistematicamente negligenciados no Brasil e, a rigor, desconsiderando as poucas experiências inovadoras na área, pode-se afirmar que não dispomos de uma política específica voltada para esse fim. Sabemos que os conceitos de prevenção e responsabilização não são excludentes nem devem ser interpretados como pólos representativos do que seriam, respectivamente, políticas criminais 'macias' ou 'duras'. Em alguns casos específicos, os mecanismos de responsabilização criminal -incluindo pena de prisão - podem construir respostas desencorajadoras ao crime e, nesse sentido, prevenir a sua ocorrência. Em outros casos, esses mecanismos não surtirão qualquer efeito e, na maioria das vezes, terminarão tendo efeitos criminógenos - ou seja, não irão prevenir o crime, mas sim produzi-lo e agravá-lo. O que deveríamos ter em mente, então, são os resultados que podemos alcançar com cada programa ou iniciativa política na área de segurança pública, pouco importando os rótulos que possam acompanhar cada abordagem. $\mathrm{O}$ imperativo aqui, mantido um compromisso basilar com os direitos humanos, é o da eficiência de uma intervenção pública" (ROLIM, 2006, p. 111).

${ }^{21}$ Prevenção e repressão não podem ser concebidas como opostos e excludentes, pois isso reduziria a capacidade do Estado de prover a ordem pública com efetividade. Essa falsa dicotomia impede que a ação estatal abarque de forma simultânea as diversas dimensões do fenômeno criminoso, fazendo com que muitas políticas de segurança pública tenham a efetividade comprometida (SAPORI, 2007).
} 
É de se notar que cada lugar possui uma realidade criminógena específica ${ }^{22}$, não sendo possível a formulação de políticas de prevenção da violência de maneira geral (a realidade, por exemplo, da criminalidade que emerge no Rio de Janeiro tem origem criminológica diversa da realidade do interior do Maranhão).

Portanto, parece não ser adequado que a formulação de políticas públicas de prevenção da violência e da criminalidade desconsidere a ótica local com participação e articulação com os Municípios, sob pena de se tornarem ineficazes.

Mas, há que se indagar, como se daria a participação dos Municípios na questão da segurança pública? Sobre o tema, Barbosa (2008), lembra que o mesmo pode atuar através de ações propositivas ou diretivas, complementando, em determinadas situações, as estratégias de repressão qualificada, bem como procedendo, diretamente, à identificação e administração dos conflitos de acordo com a sua natureza, sua especificidade, à redução dos riscos e à promoção da civilidade.

No que diz respeito à violência no trânsito, por exemplo, o Município, através do direito administrativo, possui função essencial, cabendo a ele a organização do trânsito, conforme a sua especificidade geográfica e urbana $^{23}$.

\section{A MUNICIPALIZAÇÃO DA SEGURANÇA PÚBLICA}

\section{Municipalidade e federalismo}

A Constituição da República de 1998 modificou de forma profunda a posição dos Municípios na Federação - já que os alçou como componentes da estrutura federativa - ao lhes conceder uma qualificação especial de conteúdo político de extrema importância para a definição de seu status constitucional na organização do Estado brasileiro, em hipótese não prevista sob os regimes constitucionais anteriores (SILVA, 2009), como fez, por exemplo, nos arts. $1^{24} \mathrm{e} 18^{25}$.

Assim, o Município brasileiro foi erigido como ente estatal integrante da Federação, sendo dotado de autonomia política, administrativa e financeira. Ao lado dessas características, a nova realidade política do Município brasileiro teria que vir acompanhada de consequências, como o reconhecimento constitucional de sua

\footnotetext{
${ }^{22}$ Sobre os ensinamentos da Escola de Chicago, cfr. Tangerino (2007). Sobre o mesmo assunto, realidade criminológica específica de cada lugar, Soares (2005) leciona que várias são as matrizes da criminalidade e suas manifestações variam conforme as regiões do país e dos estados, o que impossibilitaria soluções uniformes, tipo camisas-de-força, o que reforça o entendimento aqui abordado.

${ }^{23}$ A competência do Município, em matéria de trânsito, é definida no art. 24 do Código de Trânsito Brasileiro.

${ }^{24}$ Art. $1^{\circ}$ A República Federativa do Brasil, formada pela união indissolúvel dos Estados e Municípios e do Distrito Federal, constitui-se em Estado Democrático de Direito e tem como fundamentos:

${ }^{25}$ Art. 18. A organização político-administrativa da República Federativa do Brasil compreende a União, os Estados, o Distrito Federal e os Municípios, todos autônomos, nos termos desta Constituição.
} 
capacidade de auto-organização mediante leis orgânicas próprias e a da ampliação de suas atribuições (SILVA, 2009), como foi disciplinado, em boa medida, nos arts. $23^{26}$ e $30^{27}$ da Constituição.

Dessa forma, partindo do pressuposto segundo o qual a Federação reconhece por finalidade a manutenção da existência política de todos os seus membros (SCHMIT, 2011) ${ }^{28}$, há que se reconhecer maior participação aos Municípios em assuntos que dizem respeito especificamente à sua realidade, a exemplo da violência e da criminalidade urbana. Isso em nenhum momento afronta a chamada homogeneidade federal de que tratam os constitucionalistas, segundo a qual o desenvolvimento da democracia está na unidade homogênea do povo que ultrapassa as fronteiras políticas dos membros da Federação e suprime as situações de diferença em favor de uma unidade comum ${ }^{29}$.

Nesse cenário, a função federativa desempenhada pelo Município brasileiro parece ser semelhante à de uma criança que vai recebendo, aos poucos, responsabilidades pelos pais, na medida em que vai crescendo e que vai tomando discernimento acerca da importância de seu papel, até alcançar a sua autonomia.

\section{O Município como espaço primário de resolução de conflitos}

O Município é o marco, por excelência, da convivência civil devido aos interesses que the são próprios e, também, pela própria espontaneidade dos agrupamentos humanos, erigindo-se como a principal e primária

\footnotetext{
${ }^{26}$ Art. 23. É competência comum da União, dos Estados, do Distrito Federal e dos Municípios: I - zelar pela guarda da Constituição, das leis e das instituições democráticas e conservar o patrimônio público; II - cuidar da saúde e assistência pública, da proteção e garantia das pessoas portadoras de deficiência; III - proteger os documentos, as obras e outros bens de valor histórico, artístico e cultural, os monumentos, as paisagens naturais notáveis e os sítios arqueológicos; IV - impedir a evasão, a destruição e a descaracterização de obras de arte e de outros bens de valor histórico, artístico ou cultural; $\mathrm{V}$ - proporcionar os meios de acesso à cultura, à educação e à ciência; VI - proteger o meio ambiente e combater a poluição em qualquer de suas formas; VII - preservar as florestas, a fauna e a flora; VIII - fomentar a produção agropecuária e organizar o abastecimento alimentar; IX - promover programas de construção de moradias e a melhoria das condições habitacionais e de saneamento básico; X - combater as causas da pobreza e os fatores de marginalização, promovendo a integração social dos setores desfavorecidos; XI - registrar, acompanhar e fiscalizar as concessões de direitos de pesquisa e exploração de recursos hídricos e minerais em seus territórios; XII - estabelecer e implantar política de educação para a segurança do trânsito. Parágrafo único. Leis complementares fixarão normas para a cooperação entre a União e os Estados, o Distrito Federal e os Municípios, tendo em vista o equilíbrio do desenvolvimento e do bem-estar em âmbito nacional.

${ }^{27}$ Art. 30. Compete aos Municípios: I - legislar sobre assuntos de interesse local; II - suplementar a legislação federal e a estadual no que couber; III - instituir e arrecadar os tributos de sua competência, bem como aplicar suas rendas, sem prejuízo da obrigatoriedade de prestar contas e publicar balancetes nos prazos fixados em lei; IV - criar, organizar e suprimir distritos, observada a legislação estadual; V - organizar e prestar, diretamente ou sob regime de concessão ou permissão, os serviços públicos de interesse local, incluído o de transporte coletivo, que tem caráter essencial; VI - manter, com a cooperação técnica e financeira da União e do Estado, programas de educação infantil e de ensino fundamental; VII - prestar, com a cooperação técnica e financeira da União e do Estado, serviços de atendimento à saúde da população; VIII - promover, no que couber, adequado ordenamento territorial, mediante planejamento e controle do uso, do parcelamento e da ocupação do solo urbano; IX - promover a proteção do patrimônio histórico-cultural local, observada a legislação e a ação fiscalizadora federal e estadual.

${ }^{28}$ Ainda, sobre Federação, cfr. Schmit (2011), em especial a quarta seção, que trata a respeito da Teoría Constitucional de la Federación.

${ }^{29}$ Sobre a homogeneidade federal, cfr: Schmit (2011).
} 
entidade territorial na qual se produz a interação de direitos e liberdades dos indivíduos (ORTUÑO RODRIGUEZ, 2010).

A partir desse espaço primário, local de serviços, bens, instalações, elementos e infraestruturas se derivam um conjunto de relações humanas denominadas de convivência, relações que precisam de uma série de regras para que possam ser efetivadas, fundadas no princípio do respeito aos direitos e liberdades legítimos dos demais, normas as quais integram o conceito de civismo, que pode ser denominado como o comportamento respeitoso do cidadão com as normas de convivência pública (ORTUÑO RODRIGUEZ, 2010) ${ }^{30}$.

Ademais, tem sido tendência, nas mais diversas políticas públicas, que as decisões públicas sejam adotadas, se possível, pelas instâncias mais próximas dos cidadãos, a exemplo dos entes locais, favorecendo-se maior participação, transparência e controle sobre as ações do poder público (PORRAS RAMIREZ, 2001), no que se inclui a questão da segurança pública.

No entanto, no direito brasileiro, mesmo diante da escala crescente de atribuições dos Municípios, há assuntos, podendo-se incluir a segurança pública, os quais ainda são tratados de forma conservadora, porque não se reconhece, no plano prático, a relevância da municipalidade.

A notória concentração de poderes e receitas na União, principalmente, e nos Estados, deixa os Municípios a míngua de poderes normativos e de recursos para a implantação das mais diversas políticas públicas.

Por sua vez, o fenômeno da violência ${ }^{31}$, fruto da violência estrutural ${ }^{132}$, sob as suas diversas formas, é mais dinâmico do que a lenta e burocrática estrutura política e administrativa da Federação brasileira, atingindo específica e diretamente os níveis localizados da população, tendo se mostrado insuficiente o controle da formulação e implantação das políticas públicas de segurança pública em mãos da União e dos Estados, detentores de muitos poderes, mas pouco conhecedores das necessidades locais. Aliás, apenas recentemente se percebeu que não se podia deixar a questão da segurança pública centrada nos Estados, passando a União a intervir ativamente nas políticas públicas do setor.

Há de se lembrar, ainda, que a segurança pública, conforme Kahn $(2005)^{33}$, vem deixando, progressivamente de ser um tipo de atividade predominantemente estadual, ante a corrosão da atuação dos

\footnotetext{
${ }^{30}$ Além do mais, o postulado do civismo atua como modo condutor dos comportamentos humanos dentro do âmbito espacial e organizado no qual se desenvolve a vida das pessoas, isto é, cidades ou Municípios (ORTUÑO RODRIGUEZ, 2010).

31 "Juntos, a desigualdade social abissal, os serviços públicos deficientes ou inexistentes e o extremo desemprego e subemprego no contexto de uma economia urbana polarizante e de um sistema de justiça corrupto alimentaram o inexorável crescimento da violência criminal que tem sido a calamidade das grandes cidades do Brasil e da maioria dos países da América Latina" (WACQUANT, 2007, p. 205).

${ }^{32}$ Sobre violência estrutural, $c f r$. Baratta (1993).

${ }^{33} \mathrm{O}$ mesmo autor (Kahn, 2005) cita as seguintes medidas preventivas que podem ser utilizadas pela municipalidade: benfeitorias urbanas (iluminação, limpeza, poluição sonora, visual e ambiental); medidas para ampliar a educação, cultura, esportes e lazer para os jovens, especialmente das periferias, atuação em parceria com o governo estadual; criação de uma Secretaria Municipal de Segurança Pública; criação de conselhos de segurança com a participação da comunidade e em descentralização das ações; vol.07, nº. 02, Rio de Janeiro, 2014. pp. 812-839 
Estados, provocadas pelas iniciativas comunitárias de autodefesa, pela expansão das atividades da indústria da segurança e pela crescente participação da União e dos Municípios na questão; tal erosão da atuação estadual teve como causa o aumento da criminalidade, o sentimento de insegurança e o reconhecimento de que o poder público estadual não atende às necessidades específicas de segurança demandadas pela sociedade, sendo que, por outro lado, o Município tem em suas mãos instrumentos extremamente importantes para colaborar com a questão, principalmente sob sua perspectiva preventiva, abordagem deste estudo.

\section{A criminalidade como problema local}

A estrutura política de uma sociedade nada mais é do que o modo pelo qual os diferentes segmentos que a compõem tomaram o hábito de viver uns com os outros (DURKHEIM, 1995) ${ }^{34}$. Nessa perspectiva, o crime é encarado como fenômeno que faz parte da sociedade ${ }^{35}$, devendo, contudo, ser mantido em níveis toleráveis.

A manutenção da criminalidade em níveis toleráveis tem sido, dessa forma, um dos grandes problemas a ser tratado nas cidades brasileiras, já que a sensação de insegurança assola boa parte da população. Beato Filho (2012, p. 146-147) recorda que

"em sua concepção clássica, as cidades foram criadas justamente para a segurança de seus habitantes, que encontraram nelas um espaço de proteção e liberdade fora dos laços do sistema feudal; o desenvolvimento da cidadania, a racionalidade econômica, o sistema de leis universalistas e as novas formas de associação entre indivíduos advêm do desenvolvimento das cidades".

Inversamente, modernamente, o desenvolvimento dos centros urbanos se tornou sinônimo de medo e crime, restringindo sob as mais diversas formas as liberdades básicas de seus habitantes, bem como aumentando a sensação de insegurança.

campanhas de mobilização, conscientização e informação cidadã contra armas, discriminação e violência; fiscalização e concessão de alvarás para estabelecimentos que têm envolvimento frequente com crimes e contravenções, como desmanches e bordéis, policiamento preventivo, a pé, e integração com a comunidade.

${ }^{34}$ Caso as relações sejam tradicionalmente estreitas, os segmentos tendem a se confundir ou, de modo contrário, tendem a se distinguir, na medida em que tais relações se dissipam. Assim, o criminoso não aparece mais como um ser radicalmente insociável, espécie de parasita, corpo estranho e alienígena, introduzido no seio da sociedade; contrariamente, constitui um agente regular da vida social. Desse modo, crime e violência necessitam ser encarados sob uma perspectiva realística e da qual não se pode fugir, mas preveni-los e deixa-los em níveis toleráveis (DURKHEIM, 1995).

35 "O crime é, pois, necessário; ele se liga às condições fundamentais de toda a vida social e, por isso mesmo, tem sua utilidade; pois estas condições de que é solidário são elas próprias, indispensáveis à evolução normal da moral e do direito. [...] Ora, se não existissem crimes, esta condição não se verificaria; pois tal hipótese supõe que os sentimentos coletivos teriam alcançado um grau de intensidade sem exemplo na história. Nada é bom nem indefinidamente, nem desmedidamente. [...] Para que evolua, é preciso que a originalidade individual possa vir a lume; ora, para que a originalidade do idealista, que sonha ultrapassar seu século, se manifeste, é necessário que a do criminoso, que está abaixo do seu tempo, seja possível. Uma não existe sem a outra” (DURKHEIM, 1995, p. 61). Contemporaneamente, existem vários fatores que afetam a escolha do crime por parte de um indivíduo, tais como predisposições pessoais, as forcas socializantes da família, dos pares e da escola, a capacidade de autocontrole e os reforços proporcionados pela comunidade, além dos arranjos institucionais (BEATO FILHO, 2012), o denominado controle social informal. 
Desse modo, é possível resgatar as lições deixadas pela Criminologia Crítica $^{36}$ e se pensar o fenômeno da violência como decorrente da violência estrutural (injustiça social) que ocorre nas cidades e que precisa ser deixado em níveis toleráveis.

A Criminologia $\mathrm{Critica}^{37}$ apresentou alguns caminhos, já que além da teoria do direito penal mínimo, deixou uma política criminal alternativa, baseada no princípio geral de prevenção ${ }^{38}$, segundo o qual o controle deve ser eficaz e real e não simbólico, dirigindo-se às causas e não somente às manifestações dos conflitos de violência, tendo por objeto situações e não somente comportamentos dos atores implicados nela, devendo agir sobre o contexto geral do problema.

Portanto, pela via da lógica, avulta o Município como o ator mais recomendado para atuar em tal perspectiva, vez que se afigura como o ente público que reúne melhores condições, até pela proximidade com os problemas comunitários, para atuar na prevenção dos atos delinquenciais, conforme será mais aprofundado adiante.

\section{O MUNICÍPIO E AS POLÍTICAS DE SEGURANÇA PÚBLICA: REFLETINDO A RESPEITO DAS POSSIBILIDADES DE ATUAÇÃO}

\section{Da ausência de vedação constitucional em relação à participação dos Municípios em segurança pública}

Um dos grandes equívocos, quando se trata a respeito da discussão da municipalização da segurança pública, é imaginar que a mesma consistirá em mais repressão e fortalecimento do Estado punitivo em face dos cidadãos, pois ainda é fortemente arraigada a ideia de se relacionar municipalização da segurança com mais policiamento a cargo das Guardas Municipais.

Efetivamente, os constituintes recusaram várias propostas no sentido de se instituir alguma forma de Polícia Municipal, sendo que os Municípios não ficaram com nenhuma responsabilidade específica pela segurança pública, salvo a responsabilidade por ela na medida em que sendo ente estatal não poderiam se eximir de ajudar os Estados no cumprimento dessa função (SILVA, 2009).

No entanto, quando se trata da repartição constitucional de competências, o ponto fundamental é da ausência de vedação constitucional a respeito da participação dos Municípios na prevenção da violência. O fato

\footnotetext{
${ }^{36}$ Cfr. Baratta (2002) e Andrade (2003a).

${ }^{37}$ Cfr. Baratta (2002).

${ }^{38}$ Propostas da política alternativa da Criminologia Crítica: a) o controle deve se basear numa estratégia global que leve em consideração toda a fenomenologia da violência e não diminuta parcela dela; b) o controle deve se pautar nos princípios da igualdade e legalidade, evitando a discriminação dos mais fracos e a impunidade dos mais abastados; c) o controle deve ser eficaz e real e não simbólico, dirigindo-se às causas e não somente às manifestações dos conflitos de violência, tendo por objeto situações e não somente comportamentos dos atores implicados nela, devendo agir sobre o contexto da agressão (princípio geral de prevenção), assim como deve considerar o infrator em sua identidade atual (BARATTA, 1993).
} 
do texto constitucional determinar a distribuição de competência dos órgãos de segurança pública, ou seja, determinar quais órgãos devem executar obrigatoriamente as políticas de repressão à criminalidade e violência, não implica em dizer que os Municípios não possam agir de forma preventiva.

Em diversos lugares nos quais a violência foi combatida de forma efetiva, como se verá adiante, foi no âmbito local que surgiram as novas políticas de prevenção. Ortuño Rodríguez (2010), com base no parâmetro espanhol, lembra que a organização política e administrativa dos Municípios tem como objeto e como finalidade o governo e a gestão de uma série de competências que pertencem às entidades locais básicas, acervo de atribuições, que precisam ser resgatados, fortalecendo-se a legislação nos âmbitos territoriais locais, vinculando-as ao civismo ${ }^{39}$.

A evolução da esfera municipal exige que o poder público adapte-se às novas situações que, cotidianamente, emergem nas cidades, não apenas disciplinando comportamentos proibidos ou um conjunto de deveres que devem ser cumpridos, sob pena de sancionamento, exigindo atuação preventiva, através de medidas educativas, de assistência social, de fomento de ações favoráveis à urbanidade, favorecendo a normalidade das relações entre os indivíduos. Dessa maneira, as entidades locais que integram a administração municipal devem gozar de um âmbito de autonomia constitucionalmente consagrado e garantido (legislar sobre interesse local), dentro de sua esfera de interesses, denominado autonomia local, para cuja existência ontológica e prática resulta na possibilidade de que as mesmas tenham a possibilidade de impor conseqüências negativas (sanções) àqueles que praticam atos contrários às normas jurídicas aplicáveis em seus limites territoriais (ORTUÑO RODRIGUEZ, 2010).

\section{Resgatando o conceito de comunidade, de espaço e de serviços públicos}

Uma sociedade justa requer um arraigado sentimento de comunidade, como forma de incutir nos cidadãos uma preocupação com o todo, ou seja, uma dedicação ao bem comum; uma sociedade que tenha a pretensão de ser justa não pode ser indiferente às atitudes e disposições, aos hábitos do coração que os cidadãos levam para a vida pública, mas precisa encontrar meios de se afastar das noções da boa vida baseada em conceitos egoístas, havendo necessidade de se cultivar a virtude cívica (SANDEL, 2012).

\footnotetext{
${ }^{39}$ Os entes locais podem regulamentar condutas que afetam a segurança da cidade, na medida em que tais condutas se realizam em seu território de atuação. A falta de uma política de zoneamento ou a não aplicação da mesma, caso existente, por exemplo, disciplinando a existência de estabelecimentos que promovem a venda massiva de bebidas alcoólicas, falta de fiscalização em locais e estabelecimentos que promovem a prostituição, inclusive em via pública, omissão de fiscalização na venda de produtos falsificados, omissão no combate ao vandalismo, dentre outras condutas, podem constituir fatores potencializadores de violência (ORTUÑO RODRÍGUEZ, 2010).
} 
Por outro lado, a criminalidade violenta alcançou níveis tão dramáticos que se converteu em tema prioritário da agenda pública, inclusive dos Municípios, que têm rompido com dogmas e preconceitos em torno da questão, deixando a tradição de omissão e imobilismo (SOARES, 2005).

Dessa forma, a nova agenda municipal passou a incorporar a temática da segurança pública, abordando a violência criminal, sobretudo sob o aspecto preventivo, através de políticas sociais de tipo específico, inteligentes e articuladas, intersetoriais e criativas, que focalizem com prioridade os jovens vulneráveis e interceptem as dinâmicas geradoras da violência (SOARES, 2005).

Contudo para haver sucesso, é preciso que a política de segurança municipal conte com parcerias com o Estado, seus órgãos sociais e suas polícias, com o governo federal e com a sociedade civil. As razões de êxito seriam (SOARES, 2005):

a) Decorrentes do trabalho de especial qualidade da polícia, aprofundando sua colaboração operacional, investindo nas relações comunitárias, focalizando a repressão às armas, patrulhando áreas segundo diagnósticos consistentes, combinando uma presença estrategicamente orientada, ações eficientes, investigações sérias e respeito aos direitos humanos;

b) Os governos municipais, através de seus órgãos e entidades, instituições ou unidades locais, teriam de aceitar o desafio de investir na intensificação e na qualificação de suas iniciativas, e de integrar as suas ações;

c) As unidades governamentais locais deveriam procurar estender e aprofundar sua interlocução com a comunidade, através de múltiplas iniciativas;

d) A comunidade local deveria ser sensibilizada para a importância de que reaja positivamente à atenção múltipla, confluente e constante dos agentes públicos (reforço de pertencimento a um espaço urbano revalorizado e cooperativa construção dialógica da paz).

Analisando a vida americana, Sandel (2012) lembra que o fosso entre ricos e pobres enfraquece a solidariedade que a cidadania democrática requer. Crescendo a desigualdade, passam ricos e pobres a levar vidas cada vez mais distintas ${ }^{40}$. Afastando-se os ricos e as classes médias dos logradouros e serviços públicos, deixandoos para os que não podem usufruir outro tipo de serviço, aparece um efeito negativo de duas ordens: fiscal e cívico $^{41}$. Dessa forma, instituições que antes reuniam pessoas e desempenhavam o papel de escolas informais da

\footnotetext{
${ }^{40}$ Para Sandel (2012), o rico envia seus filhos para escolas particulares, deixando a escola pública para os filhos das famílias que não tem recursos. A mesma tendência se apresenta em relação a outros serviços públicos, levando ao afastamento dos privilegiados (academias privadas que substituem os centros recreativos e as piscinas comunitárias; empreendimentos residenciais de alto padrão com segurança própria e que não dependem da proteção da polícia; um segundo ou terceiro carro acabando com dependência do transporte público etc.).

${ }^{41}$ Deteriorando-se os serviços e logradouros públicos, aqueles que não precisam mais deles não têm interesse em apoiá-los com seus impostos; o efeito cívico é que instituições públicas como escolas, parques, pátios recreativos e centros comunitários deixam de ser locais onde cidadãos de diferentes classes econômicas se encontram (SANDEL, 2012).
} 
virtude cívica estão cada vez mais raras e afastadas, esvaziando o domínio público e dificultando o hábito da solidariedade e do senso de comunidade dos quais depende a cidadania democrática.

E é nessa perspectiva de resgate do civismo que as propostas de prevenção da violência surgem, tendo o Município como um de seus principais fomentadores, tendo-se como um dos fundamentos teóricos a Escola de Chicago, através do controle social informal.

\section{O controle social informal de áreas criminais: perspectivas a partir da Escola de Chicago}

Incialmente, não se desconhece que as lições da Escola de Chicago devem ser utilizadas com prudência, evitando-se o discurso criminalizador baseado na origem social ${ }^{42}$, não se podendo utilizar os ensinamentos das teorias ecológicas de modo indiscriminado, utilizando-as para fixar seletividade de populações vulneráveis (ANIYAR DE CASTRO, 2009). Contudo, é inegável que a Escola de Chicago deixou ensinamentos profícuos a respeito da desorganização do espaço urbano e o fenômeno da violência, as quais podem ser utilizadas, com a devida prudência como forma de política de prevenção de violência e criminalidade.

Em obra a respeito da relação entre crime e o ambiente urbano, tendo como aporte teórico a Escola de Chicago, Tangerino (2007) ${ }^{43}$ analisou que a criminalidade pode ser prevenida com o fortalecimento das instituições locais, a partir do controle social informal, já que, em muitas cidades, a exemplo de São Paulo, utilizada como referencial, a violência urbana não está associada a determinadas pessoas previamente selecionadas como criminosas, mas associada a determinadas "áreas criminais", nas quais a criminalidade surge não pelas pessoas que habitam tais áreas, mas pelo grau de deterioração habitacional, urbana e social de que são vítimas, vinculando-se o crime não a tipos ou perfis de pessoas, mas a perfis de áreas urbanas degradadas, nas quais são frágeis ou inexistentes os vínculos sociais.

Nesse sentido, a municipalidade poderia agir com a implementação de políticas públicas preventivas, através do controle social informal, no lugar de políticas repressivas, recuperando-se espaços e serviços públicos

\footnotetext{
${ }^{42}$ Sobre a crítica ao uso indiscriminado das teorias ecológicas, cfr. Aniyar de Castro (2009), para quem a criminologia, não raras vezes, tem se apresentado cada vez mais regressiva, voltando, com muita aceitação, a velhos estudos genéticos ou até aos novos conceitos de populações vulneráveis com elementos característicos da pobreza, revivendo, por exemplo, nos Estados Unidos, a teoria ecológica da Escola de Chicago, com o conceito de desorganização social, para investigar, em zonas de imigrantes, as diferenças delitivas entre famílias mexicanas, peruanas e colombianas. Para a autora, a criminologia do primeiro mundo, agora, se divide entre uma esquerda que se autodenomina por sua tendência humanista e uma direita que se caracteriza por feições fascistas, lembrando que há várias investigações norte-americanas e europeias que tentam explicar suas delinquências através de traços étnicos, antropológicos ou culturais dos imigrantes do terceiro e quartos mundos, investigações cujas recomendações se dividem entre dois extremos: criminalizar ou integrar.

${ }^{43}$ Veja-se, também, a abordagem de Diniz (2005), para quem a criminalidade emerge como conseqüência de problemas associados a mecanismos de controle social, podendo as comunidades locais, marcadas por um complexo sistema de associações formais e informais, de relações de amizades e parentescos, contribuir para o processo de socialização e aculturação do indivíduo; por outro lado, quando há a quebra dessa coesão social e de controle social informal, abrindo-se perspectivas para as práticas criminais.
} 
degradados, conjuntamente com o fortalecimento dos laços sociais comunitários, integrando-se e recuperando-se as áreas degradadas, para se oferecer espaços públicos capazes de agregar o sentimento de comunidade e de civilidade.

As propostas de Tangerino (2007), a respeito de medidas de prevenção da criminalidade urbana no Município de São Paulo, poderiam ser utilizadas por outros Municípios brasileiros, adaptados, logicamente, a suas realidades ou, inclusive, inovando-se com medidas que se adéquem a suas conjunturas delitivas. Tais medidas seriam:

a) Intervenções urbanísticas ${ }^{44}$, como a estruturação da rede de transporte público de massas eficiente e integrado entre todas as regiões da cidade; recuperação de áreas fisicamente degradadas; criação de espaços públicos com vistas à integração social local, como parques, clubes, espaços culturais, quadras esportivas etc. ${ }^{45}$; aprimoramento dos programas de zoneamento da cidade, bem como de sua fiscalização, de modo a desestimular o convívio de áreas habitacionais com áreas industriais; estímulo à ocupação das unidades desocupadas no centro da cidade, possibilitando a residência de classes sociais diferentes em uma mesma área, fortalecendo os aspectos de segurança urbana;

b) Intervenções de reforço do controle social informal, como o desenvolvimento de projetos de organizações não governamentais, especialmente junto à juventude no sentido de compreender criticamente a natureza comunitária da criminalidade, entender a dinâmica criminal da comunidade, explorar meios de intervenção da própria comunidade naquela realidade específica e explorar e direcionar as demandas ao poder público atinentes ao diagnóstico traçado; desenvolvimento de medidas que estimulem uma nova relação com os órgão estatais que não componham o sistema de justiça crimina ${ }^{46}$ modernização do modelo de gestão dos órgãos públicos, com a inclusão do público-alvo desses órgãos no planejamento e execução das tarefas.

\footnotetext{
${ }^{44}$ Algumas dessas considerações já são determinadas pelo Estatuto das Cidades (Lei n. 10.257/2001), ao dispor, no art. 2º , que a política urbana tem por objetivo ordenar o pleno desenvolvimento das funções sociais da cidade e da propriedade urbana, mediante as seguintes diretrizes, dentre outras: oferta de equipamentos urbanos e comunitários, transporte e serviços públicos adequados aos interesses e necessidades da população e às características locais; ordenação e controle do uso do solo, de forma a evitar a utilização inadequada dos imóveis urbanos, a proximidade de usos incompatíveis ou inconvenientes, a deterioração das áreas urbanizadas, a poluição e a degradação ambiental; justa distribuição dos benefícios e ônus decorrentes do processo de urbanização; e adequação dos instrumentos de política econômica, tributária e financeira e dos gastos públicos aos objetivos do desenvolvimento urbano, de modo a privilegiar os investimentos geradores de bem-estar geral e a fruição dos bens pelos diferentes segmentos sociais. Sobre degradação urbana e prevenção criminal, cfr. Vendramini (2010) e Kahn (2005).

${ }^{45}$ Neste ponto, o autor sugeriu que, se possível, em virtude da viabilidade estratégica ou econômica, realizar consulta prévia à população de qual o aparelho seria mais desejado na região, de modo a potencializar o impacto do mesmo, bem como a criação de um conselho gestor desses espaços, impulsionando a participação popular nos mesmos, com a consequente apropriação da cosia pública pela comunidade.

${ }^{46} \mathrm{O}$ autor sugere que a utilização da escola pública não apenas como espaço onde se realizam aulas, mas como verdadeiro núcleo de socialização, aproximando pais e população do entorno para a gestão e utilização da mesma; expansão de programas públicos que facilitem a cidadania formal, reunindo diversos órgãos públicos em um único prédio; criação de espaços de mediação de conflitos comunitários.
} 


\section{A perspectiva de prevenção da violência a partir do âmbito local}

Além das propostas acima elencadas, outros autores apresentam perspectivas de prevenção da violência a partir do âmbito local, em propostas que envolvem a participação dos Municípios brasileiros.

Barbosa (2008), por exemplo, sugere que cabe ao Município a identificação da natureza dos conflitos e sua administração institucional, cabendo-lhe desenvolver ações no sentido de romper com o modelo de controle social em que a informação é apropriada de forma particularizada, e sugere diversas medidas de cunho preventivo $^{47}$.

Renato Sérgio de Lima (2011), por sua vez, lembra que o aumento da violência e da criminalidade nos anos 80 a 90 gerou a necessidade dos Municípios atuarem preventivamente, em uma ótica baseada na lógica local, provocando-se uma mudança de olhar, do repressivo para o preventivo, e deslocando a visão do crime para a violência, em que medidas e intervenções no cenário urbano seriam uma justificativa para alterar o quadro de insegurança. Este autor sugere que o Município possa atuar a partir de cinco políticas de prevenção: criação de Guardas Municipais; institucionalização de conselhos, secretarias e planos municipais de segurança; acesso dos Municípios aos recursos do Fundo Nacional de Segurança Pública; e, em determinadas cidades, criação de lei de restrição de funcionamento de bares e venda de bebidas alcoólicas.

Luís Flávio Sapori (2007) cita o caso da cidade de Bogotá, na Colômbia, que, com medidas preventivas, conseguiu reduzir os altos índices de criminalidade ${ }^{48}$, após tomar as seguintes medidas: controle do consumo de bebidas alcoólicas e do uso de armas de fogo; recuperação de espaços urbanos deteriorados, inclusive com intervenções em bairros nos quais predominavam vendedores informais; estímulo à participação comunitária; fortalecimento da polícia, com investimentos em infraestrutura logística, física e capacitação, bem como avaliação de resultados dos departamentos de polícia; ampliação das carceragens municipais; prevenção da violência doméstica, com equipes multidisciplinares compotas por advogados, psicólogos, médicos e assistentes sociais; implantação de mecanismos alternativos de resolução de conflitos cotidianos, intrafamiliares ou entre vizinhos, inclusive com a utilização da estrutura de polícia administrativa e judiciária.

\footnotetext{
${ }^{47}$ Mencione-se: a) criação de um sistema de informações; b) campanhas de esclarecimento junto à população no que diz respeito ao exercício dos seus direitos e aos benefícios obtidos quando da explicitação das regras e de sua aplicação, promovendo, assim, a civilidade no espaço público; c) promoção de ações direcionadas considerando a especificidade das políticas de redução de risco (no trânsito, nas escolas, na área da saúde, nas ações que envolvem impacto ambiental, uso e abuso de drogas lícitas e ilícitas, dentre outras).

${ }^{48}$ Segundo o autor, entre 1994 a 2002, com uma política local, baseada em prevenção e repressão, de formas conjuntas, conseguiu reduzir de 80 homicídios por 100 mil habitantes, no ano de 1993, contrastando com 22 por 100 mil habitantes, em 2003 entre 1994 a 2002, com uma política local, baseada em prevenção e repressão, de formas conjuntas, conseguiu reduzir de 80 homicídios por 100 mil habitantes, no ano de 1993, contrastando com 22 por 100 mil habitantes, em 2003.
} 
Perceba-se que as propostas dos vários autores citados não têm a pretensão de usurpar a função de polícia ostensiva, seja da União ou dos Estados, mas, simplesmente, aperfeiçoar tal sistema, sob o viés preventivo a partir da formulação e implantação de políticas públicas.

Não se pode esquecer que o art. $182^{49}$ da Constituição Federal estabelece que deve haver uma política de desenvolvimento urbano a cargo do Município, a qual assegure o bem-estar de seus habitantes. Ora, inevitavelmente, o "bem-estar de seus habitantes", do qual fala a Constituição, diz respeito, também, à segurança pública, já que o mesmo foi alçado como direito social, previsto no art. $70^{50}$.

No sentido da argumentação acima, convergente é o entendimento de que existem determinados fatores que aumentam o risco da criminalidade e da violência: a) o consumo de bebidas alcoólicas, principalmente quando as autoridades públicas não exercem qualquer fiscalização nos estabelecimentos, permitindo, inclusive, que muitos funcionem sem qualquer autorização ou, até mais grave, permitindo a venda avulsa das mesmas por ambulantes em locais públicos; b) o acesso a armas de fogo (felizmente, em nível legislativo, de uso restrito); c) cultura de resposta violenta aos conflitos interpessoais, como as discussões de trânsito, não raras vezes geradas pela deficiência ou ausência de fiscalização pela municipalidade; d) formação de gangues de jovens; e) deterioração do espaço urbano (SAPORI, 2007).

Consequentemente, de posse de dados sérios a respeito da incidência de crimes em determinada cidade, parece ser possível, por exemplo, pela via de ações do Município, prevenir determinados delitos. Se em determinado bairro há a incidência de gangues infanto-juvenis, deveria o Município ser instado a agir formulando políticas públicas direcionadas para tais pessoas (assistência social, oferta de lazer, educação, saúde, possibilidade de inserção no mercado de trabalho, apoio psicológico etc.).

Ora, se a desorganização urbana, dentre outros fatores, propicia a incidência maior de crimes, deve o Município intervir com a implementação de políticas públicas de melhoria de qualidade de vida da população, sendo ilusório pensar em qualquer medida de prevenção à violência e à criminalidade sob o viés meramente repressivo, como durante muito tempo se fez no Brasil.

Sabe-se, no entanto, que a atual realidade dos Municípios brasileiros não permite que todos venham a desempenham qualquer função que vá além da proteção de seus bens, serviços e instalações, através de Guardas Municipais (art. 144, $\$ 8^{\circ}$, da CF). A mendicância financeira e tributária de grande parte dos Municípios é uma realidade, infelizmente. Todavia, as metrópoles, as grandes e as médias cidades, que mais sofrem com o fenômeno da violência, devem ser estimuladas a participar de forma mais efetiva no combate à violência.

\footnotetext{
${ }^{49}$ A política de desenvolvimento urbano, executada pelo Poder Público municipal, conforme diretrizes gerais fixadas em lei, tem por objetivo ordenar o pleno desenvolvimento das funções sociais da cidade e garantir o bem-estar de seus habitantes.

${ }^{50}$ Art. $6^{\circ}$ São direitos sociais a educação, a saúde, a alimentação, o trabalho, a moradia, o lazer, a segurança, a previdência social, a proteção à maternidade e à infância, a assistência aos desamparados, na forma desta Constituição.
} 


\section{Os avanços e as pretensões legislativas envolvendo a municipalização da Segurança Pública: refletindo a respeito do Fundo Nacional de Segurança Pública e o Projeto de Lei que institui o Sistema Nacional de Segurança Pública}

Há um bom tempo, desde a instituição da Lei no 10.201/2001, que institui o Fundo Nacional de Segurança Pública, já não podem os Municípios assistir passivamente ao aumento das suas estatísticas criminais, sob o argumento ultrapassado segundo o qual os mesmos não têm atribuição para atuar na área de segurança pública.

A atuação daqueles é baseada nos modernos conceitos de segurança pública (prevenção), estando ao seu dispor os recursos do Fundo Nacional de Segurança Pública, como prevê a Lei no 10.201/2001, a qual determina, no art. $4^{\circ}, \mathrm{V}$, que o fundo apoiará projetos destinados a programas de prevenção ao delito e à violência, sendo que o Conselho Gestor do Fundo, na avaliação de projetos, priorizará o ente federado que se comprometer com resultados, dentre outros, como a realização de diagnóstico dos problemas de segurança pública e apresentação das respectivas soluções, desenvolvimento de ações integradas dos diversos órgãos de segurança pública, qualificação das guardas municipais, redução da criminalidade e insegurança pública.

Note-se que terão acesso aos recursos do fundo o ente federado que tenha instituído, em seu âmbito, plano de segurança pública, bem como o Município que mantenha guarda municipal ou realize ações de policiamento comunitário ou, ainda, institua Conselho de Segurança Pública, visando à obtenção dos resultados.

Não é demasiado recordar que a participação da municipalidade vem ganhando força, havendo pretensões de se avançar legislativamente a respeito da questão. Exemplo claro é o projeto de lei que trata a respeito da organização e o funcionamento dos órgãos responsáveis pela segurança pública, instituindo o Sistema Único de Segurança Pública - SUSP e dispõe sobre a segurança cidadã.

No artigo $4^{\circ}$, o projeto mencionado acima estabelece que a atuação dos órgãos responsáveis pela segurança pública atenderá, dentre outros, aos princípios de resolução pacífica dos conflitos, no uso proporcional da força, e na eficiência na prevenção e repressão das infrações penais, bem como determina que a segurança pública (art. $5^{\circ}$ ) deverá ser prestada com observância das diretrizes de planejamento estratégico e sistêmico, integração dos órgãos e instituições da segurança pública, unidade de comando, coordenação por cooperação e colaboração e uso de sistema de informações e dados eletrônicos.

São perceptíveis os avanços no projeto. No entanto, quando o mesmo trata a respeito da repartição de atribuições entre União, Estados, Distrito Federal e Municípios, limita-se a dispor que as Guardas Municipais poderão colaborar em atividades suplementares de prevenção na implementação cooperativa das políticas de segurança pública dos entes federados (parágrafo único do art. $6^{\circ}$ ). O ranço policialesco, nesse ponto, é evidente, baseado no preconceito de se conceber segurança pública apenas de forma repressiva. 
Há um avanço, contudo, quando o mesmo prevê que poderão ser constituídos gabinetes de gestão integrada encarregados da implementação das políticas estabelecidas pelos Conselhos de Segurança Pública, no âmbito nacional, regional, dos Estados, do Distrito Federal e dos Municípios, os quais se nortearão pelo plano nacional de segurança pública. Infelizmente, na prática administrativa, com o sistema político atual, não é fácil conceber-se um discurso afinado entre a União, Estados e Municípios a respeito de prevenção de violência e criminalidade e segurança pública, já que, via de regra, se apresentam profundas divergências ideológicas entre os diversos gestores.

Parece, dessa maneira, que o grande avanço do projeto está no capítulo que tratará da segurança cidadã, que é definida, no art. 26, como a situação política e social de segurança integral e cultura da paz em que as pessoas têm, legal e efetivamente, garantido o gozo pleno de seus direitos fundamentais, por meio de mecanismos institucionais eficientes e eficazes de prever, prevenir, planejar, solucionar pacificamente os conflitos e controlar as ameaças, as violências e coerções ilegítimas. ${ }^{51}$

A bem da verdade, o projeto não dá soluções prontas, mas apresenta caminhos, muitos dos quais se assemelham às propostas lançadas pelos diversos autores apontados neste trabalho, como viés de controle social informal bem nítido, com segurança baseada em prevenção e não apenas em repressão, sem desconsiderar a necessidade desta última, logicamente.

Provavelmente, o projeto não avançou mais em função das dificuldades políticas em ser implementado, já que segurança pública e violência fazem parte dos discursos políticos, como forma de solução imediatista e fácil de problemas sociais, quando não se sabe ou não se quer enfrentar, efetivamente, tais problemas, ocasião na qual a legalidade do sistema penal é utilizada, simbolicamente, como justificativa para novas criminalizações ${ }^{52}$.

Por fim, apesar da apresentação das diversas propostas, é de se reconhecer que a violência, também, é uma questão de democracia ${ }^{53}$, pois, para ser prevenida, é preciso ser discutida e trabalhada com políticas públicas as quais os cidadãos, também, necessitam atuar, inclusive, cobrando dos representantes dos seus Municípios

\footnotetext{
${ }^{51}$ O projeto dispõe, também, que é de responsabilidade da União, dos Estados, do Distrito Federal e dos Municípios a construção e execução de políticas públicas voltadas para a implementação da segurança cidadã, que terá como objetivo dar efetividade às ações de prevenção da violência e da criminalidade e tem como meta garantir a inclusão social e a igualdade de oportunidades, por meio de políticas públicas que observem a prevenção primária (fatores ambientais da criminalidade), prevenção secundária (ações dirigidas a pessoas mais suscetíveis de praticar crimes), prevenção terciária (ações dirigidas a pessoas que já praticaram crimes e violências), prevenção situacional (redução das oportunidades para a prática de crimes e violências na sociedade, por meio do aumento dos custos, aumento dos benefícios ou redução dos benefícios associados à prática de crimes e violências) e prevenção social (ações dirigidas à redução da predisposição dos indivíduos e grupos para a prática de crimes e violências na sociedade, visando enfrentar os problemas de fundo que criam condições para as pessoas ou grupos que chegam a incorrer em atos delitivos).

${ }^{52}$ Sobre a utilização política da segurança pública, cff: Aniyar de Castro (2009), para quem a violência está presente na linguagem dos governos e políticos que se apresentam no período eleitoral, criando-se uma atmosfera de guerra virtual. Cffr., também, Vendramini (2010), para quem a ausência de entendimento público entre Estado e Município, ante a existência de divergências político-partidárias, produz um quadro anômalo da segurança pública, tendo como resultado a falta de planejamento conjunto, a escassez de recurso, aumento da criminalidade e péssimas condições dispensadas aos cidadãos.

${ }^{53}$ Sobre o assunto, violência como problema de democracia, cfr. Guimarães (2013).
} 
atuação mais efetiva, pois não sendo a segurança pública apenas questão de repressão, ou seja, só de Polícia, é preciso que a seja discutida e assumida por todos, Estado e população, eis que, em sua acepção constitucional, é direito, mas, igualmente, responsabilidade de todos (art. 144, caput, da CF).

\section{CONSIDERAÇÕES FINAIS}

O trabalho teve como objetivo refletir sobre as várias possibilidades, no cenário constitucional brasileiro, do Município agir na formulação e na implantação de políticas de segurança pública, principalmente sob o aspecto preventivo, através da organização do espaço urbano, da articulação com outros entes e entidades, com o resgate dos conceitos de civismo, comunidade, espaços e serviços, bem como apresentar alguns avanços legislativos, vigentes e em discussão, em torno da questão.

Para tanto, o artigo apresentou os limites constitucionais de atuação dos diversos entes federativos na área de segurança pública, observando que não há vedação constitucional para que os Municípios atuem na área de segurança pública. Para tanto, partiu-se da premissa segundo a qual a segurança pública não é apenas repressão, mas uma política pública constituída de prevenção, sendo a repressão apenas um de seus aspectos. Dessa forma, caberia ao Município agir, de forma mais enfática, nas políticas preventivas.

Para que a segurança pública se mostre efetiva, a mesma deve ser vista como um bem coletivo, a ser desfrutado por todos, sendo um serviço público a ser proporcionado por todos e não como mera forma de repressão às camadas mais pobres da população, através de um discurso criminalizador e repressor.

Sendo bem coletivo essencial, cabe a todos os entes públicos (União, Estados, Distrito Federal e Municípios) zelar pelo seu fiel cumprimento, como forma de manter a ordem pública e corresponder aos anseios dos cidadãos de se sentirem seguros e poderem desfrutar de outros direitos constitucionalmente assegurados.

Ocorre que a concepção tradicional de segurança pública deixou tal política pública concentrada em mãos dos Estados e do Distrito Federal, o que acabou por torná-la sem efetividade, já que foram pautadas principalmente sob a função repressora. A violência, por sua vez, desconhece ou faz pouco caso da estrutura burocrática do Estado, com as suas divisões de competências e atribuições entre os diversos entes.

Com a eclosão de vários problemas graves envolvendo segurança pública em diversos Estados, a União acabou tendo que intervir em diversas ocasiões e passou a pautar as discussões em torno do tema, antes monopolizados por aqueles entes, passando a cobrar mais empenho dos aspectos de prevenção e de articulação.

A segurança pública de forma preventiva e articulada pressupõe não apenas a participação dos órgãos de gestão, mas a participação da população e, no âmbito federativo, dos Municípios, maiores prejudicados em eventuais falhas das políticas de segurança articuladas pelos Estados ou pela União. 
A partir dessa maior participação dos Municípios nas políticas de segurança pública, passa-se a falar em municipalização do tema, a exemplo de outras políticas que já forma objeto de municipalização, como trânsito, saúde, educação etc.

Para tanto, verificou-se a situação dos Municípios no contexto constitucional brasileiro após a Constituição de 1988, que thes deu maior autonomia.

Considerou-se que o Município é o espaço primário de resolução de conflitos, em se considerando a estrutura federal brasileira, ou seja, é o primeiro ente a sofrer as conseqüências de uma política de segurança desarticulada ou desastrosa. É a partir dele que emergem os conflitos. Sendo ele o marco, por excelência, da convivência civil devido aos interesses que lhe são próprios e pela espontaneidade dos agrupamentos humanos, surge como a principal entidade territorial na qual se produz a interação de direitos e liberdades dos cidadãos.

Por sua vez, a segurança pública, para ser efetiva, deve pressupor também a criminalidade como um problema local, ou seja, deve considerar as diversas facetas do fenômeno criminógeno, o qual deve ser encarado como fenômeno que faz parte da sociedade, devendo, contudo, ser mantido em níveis toleráveis.

Nesse contexto, a partir desse ponto, o trabalho passou a refletir a respeito das várias possibilidades de atuação dos Municípios em relação às políticas de segurança pública. Como se mencionou acima, o primeiro ponto é reconhecer que não há vedação constitucional para que os Municípios atuem sobre o tema. O fato de a Constituição ter estruturado os órgãos de repressão em mãos dos Estados, do Distrito Federal e da União, não pressupõe que tenha vedado a participação dos Municípios sobre a questão, que se dará principalmente através de políticas públicas articuladas de prevenção da violência, considerando o contexto de cada localidade.

Procurou-se, da maneira acima, esclarecer que a municipalização da segurança pública não deve pressupor mais repressão e fortalecimento do Estado punitivo em face dos cidadãos e tentar relacionar a ideia com mais policiamento a cargo das Guardas Municipais.

As propostas que acreditam que a municipalização da segurança pública pode contribuir para a diminuição da violência, considera este fenômeno como sendo estrutural, a partir dos ensinamentos da Criminologia Crítica. E para que alce resultados promissores, deve-se resgatar o conceito de comunidade, de espaço e de serviços públicos, que pressuponha uma sociedade mais justa e que tenha arraigado um sentimento de comunidade, como forma de incutir nos cidadãos uma preocupação com o bem comum e com o civismo, inclusive para se cobrar a formulação e a execução das políticas públicas de segurança a cargo do Poder Público.

E na perspectiva de resgate do civismo, as propostas de prevenção da violência surgem tendo o Município como um de seus principais fomentadores, tendo-se como um dos fundamentos teóricos a Escola de Chicago, através do controle social informal a partir de áreas criminais, que deverão ser objeto de políticas públicas preventivas. 
A perspectiva de prevenção da violência a partir do âmbito local é objeto de estudo de vários autores, que apresentam propostas que sugerem maior envolvimento dos Municípios brasileiros em se tratando de segurança pública.

No plano legislativo, analisou-se a Lei no $10.201 / 2001$, que institui o Fundo Nacional de Segurança Pública, bem como, em seguida, os avanços e as pretensões legislativas envolvendo a municipalização da Segurança Pública em torno do Fundo Nacional de Segurança Pública e o Projeto de Lei que institui o Sistema Nacional de Segurança Pública, em que foram elencados principalmente seus pontos positivos.

\title{
REFLECTIONS ABOUT THE SEVERAL POSSIBILITIES OF A BETTER PARTICIPATION OF BRAZILIAN CITIES IN FORMULATION AND IMPLEMENTATION OF PUBLIC POLITICS FOR PUBLIC SAFETY
}

\begin{abstract}
:
This article comes up with a reflection about the several possibilities, in present constitutional scenery, of a better participation of Brazilian cities to formulate and develop public politics for public safety, mainly in a preventive aspect, through urban space organization, articulations among political groups, by recovering the concept of civility, community, spaces and services, and by showing some legislations advances about this topic, current and in question as well.
\end{abstract}

Keywords: Public security. Prevention. Brazilian cities, participation.

\section{REFERENCIAS}

AGNEW, Robert. Why do individuals engage in crime? In: Key Readings in Criminology. Devon, UK: Willan Publishing, 2009, p. 169-173.

ANDRADE, Vera Regina Pereira de. A ilusão da segurança jurídica: do controle da violência à violência do controle penal. 2. ed. Porto Alegre: Livraria do Advogado, 2003a, 336 p.

Sistema Penal Máximo x Cidadania Mínima: Códigos da Violência na Era da Globalização. Porto Alegre: Livraria do Advogado, 2003b.

ANIYAR DE CASTRO, Lola. La criminología crítica en el siglo XXI como criminología de los derechos humanos y la contra-reforma humanística o "las teorias criminológicas no son inocentes". Revista Brasileira de Ciências Criminais, vol. 76, p. 265, Jan/2009DTR \2009\15.

BARATTA, Alessandro. Criminologia crítica e crítica do Direito Penal: introdução à Sociologia do Direito Penal. 3. ed. Rio de Janeiro: Revan, 2002, 254 p. 
Direitos humanos: entre a violência estrutural e a violência penal. Fascículos de Ciências Penais. Ano 6, v. 6, n. 02, p. 44-61, abr.jun. 1993.

BARBOSA, Antonio Rafael et al. Reflexões sobre a municipalização da segurança a partir do diagnóstico de segurança pública do município de São Gonçalo (Rio de Janeiro). Revista Civitas. Porto Alegre, v. 8, n. 03, p. 386408, set.-dez. 2008.

BEATO FILHO, Claudio Chaves. Crime e cidades. Belo Horizonte: Editora UFMG, 2012, 291 p.

CANOTILHO, Gomes; MOREIRA, Vital. Constituição da República Portuguesa Anotada. 3. ed. Coimbra: Coimbra Editora, 1993.

COSTA, Ivone Freire; BALESTRERI, Ricardo Brisolla (org.). Segurança pública no Brasil: um campo de desafios. Salvador: EDUFBA, 2010, 143 p.

CHRISTIE, Nils. A suitable amount of crime. In: Key Readings in Criminology. Devon, UK: Willan Publishing, 2009, p. 17-18.

DINIZ, Alexandre M. A. Migração, desorganização social e violência urbana em Minas Gerais. RA 'E GA: o espaço geográfico em análise. Curitiba, n. 09, p. 9-23, 2005.

DURKHEIM, Émile. As regras do método sociológico. 15. ed. São Paulo: Companhia Editora Nacional, 1995, $128 \mathrm{p}$.

FERNANDES, Manuel. Urbanismo, segurança e lei. In: VALENTE, Manuel Monteiro Guedes (org.). Seminário urbanismo, segurança e lei. Tomo II. Coimbra: Almedina, 2009, p. 59-69.

GADAMER, Hans-Georg. Verdade e método: traços fundamentais de uma hermenêutica filosófica. Petrópolis: Vozes, 1997, $731 \mathrm{p}$.

GARLAND, David. Castigo y sociedad moderna. Un estudio de teoria social. Madrid: Siglo Veintiuno, 1999, 361 p.

GRAÇA, Pedro Borges. Os estudos de informações e de segurança na universidade. In: VALENTE, Manuel Monteiro Guedes (org.). Seminário urbanismo, segurança e lei. Tomo II. Coimbra: Almedina, 2009, p. 15-29.

GUIMARÃES, Claudio Alberto Gabriel. Reflexões acerca do controle social formal: rediscutindo os fundamentos do direito de punir. Revista da Faculdade de Direito da UERJ-RFD. Rio de Janeiro, v. 1, n. $23,2013$.

KAHN, Tulio. Indicadores em prevenção municipal de criminalidade. In: SENTO-SÉ, João Trajano (org.). Prevenção da violência: o papel das cidades. Rio de Janeiro: Civilização Brasileira, 2005.

LIMA, Renato Sérgio de. Entre palavras e números: violência, democracia e segurança pública no Brasil. São Paulo: Alameda, 2011,308 p.

ORTUÑO RODRIGUEZ, Alicia Esther. Civismo y convivencia municipal. Barcelona: Editorial Bayer Hnos, 2010,206 p. 
PIRES, Álvaro. A racionalidade penal moderna, o público e os direitos humanos. Revista Novos Estudos. São Paulo, n. 68, p. 39-60, mar. 2004.

PORRAS RAMÍREZ, José María. El conflito em defensa de la autonomia local ante el Tribunal Constitucional. Madrid: Civitas, 2001, 129 p.

ROLIM, Marcos. Prevenção e fatores de risco: o que pode nos dizer a moderna criminologia. In: A síndrome da rainha vermelha: policiamento e segurança pública no século XXI. Rio de Janeiro: Jorge Zahar Editora; Oxford, Inglaterra: University of Oxford, Center for Brazilian Studies, 2006, p. 104-148.

SANDEL, Michael J. Justiça: o que é fazer a coisa certa. 8. ed. Rio de Janeiro: Civilização Brasileira, 2012, 349 p.

SAPORI, Luís Flávio. Segurança pública no Brasil: desafios e perspectivas. Rio de Janeiro: Editora FGV, 2007, 208 p.

SCHMIT, Carl. Teoría de la Constitución. Madrid: Alianza Editorial, 201 1, 494 p.

SILVA, José Afonso da. Curso de Direito Constitucional Positivo. 32. ed. São Paulo: Malheiros, 2009, 926 p.

SOARES, Luiz Eduardo. Segurança municipal no Brasil: sugestões para uma agenda mínima. In: SENTO-SÉ, João Trajano (org.). Prevenção da violência: o papel das cidades. Rio de Janeiro: Civilização Brasileira, 2005.

TANGERINO, Davi de Paiva Costa. Crime e cidade: violência urbana e a Escola de Chicaco. Rio de Janeiro: Lumen Júris, 2007, 174 p.

VALENTE, Manuel Monteiro Guedes (org.). Seminário urbanismo, segurança e lei. Tomo II. Coimbra: Almedina, 2009, $165 \mathrm{p}$.

VENDRAMINI, Janio. Segurança pública nas grandes cidades brasileiras. São Paulo: Editora Navegar, 2010, 202 p.

WHITE, Rob, HAINES, Fiona, ASQUITH, Nicole. Crime and Criminology. London: Oxford Press, 2012, 333 p.

WACQUANT, Loïc. Rumo à militarização da marginalização urbana. Discursos sediciosos. Crime, direito e sociedade. Rio de Janeiro, ano 11, n. 15 e 16, p. 203-220, $1^{\circ}$ e $2^{\circ}$ semestres de 2007.

Trabalho enviado em 3 de agosto de 2014.

Aceito em 8 de setembro de 2014. 